\title{
Sexual Violence and the Plights of Internally Displaced Persons During the Covid-19 Pandemic Lockdown in Nigeria
}

\author{
Joy Nneka U. Ejikeme ${ }^{1}$, Iwundu Ifeanyi E.2 \& Ogechi Cecilia Ukaogo ${ }^{3}$ \\ ${ }^{1} \mathrm{PhD}$, Lecturer in Humanities, Humanities Unit, School of General Studies, University of Nigeria, \\ Nsukka. Email: joy.ejikeme@unn.edu.ng \\ ${ }^{2}$ Senior Research Fellow, Institute of African Studies, University of Nigeria, Nsukka \\ Email: Iwundu.ifeanyi@unn.edu.ng \\ ${ }^{3}$ Staff, Careers Unit, Registrar's Office, University of Nigeria, Nsukka. Email: oukaogo@gmail.com
}

\begin{abstract}
This paper examines the new vista opened by the outbreak of the Covid-19 pandemic specifically the issue of rape criminality in Nigeria. Regrettably, Covid-19 lockdown saw to the different dimensions to rape crime which is the household rape. In addition, this study beams its searchlight on the most vulnerable group; women and girl children affected by the Covid-19 pandemic lockdown especially those that were Internally Displaced from their homes, the IDPs. Furthermore, this study observes that the lockdown in Nigeria resulted in many deaths and injuries on the verge of enforcing the Covid-19 lockdown rules. Relevant materials for this paper have been sourced from newspapers, online publications in journals, and books while the descriptive method of analysis has been adopted.
\end{abstract}

\section{Keywords}

Rape Criminality, Sexual Violence, Covid-19, Pandemic and Internally Displaced Persons.

\section{Introduction}

An objective assessment of the impact of COVID-19 on families has been examined by scholars. Kumar (2020:193) provides an excellent analysis which insists that the pandemic has created anxiety, financial constraints leading to behavioral disorder like altercations, anger and violence. $\mathrm{He}$ also maintained that families had adequate time together, family bonding and parents were attached to their children and listening to each other (Kumar, 2020:194). For a country like Nigeria, opportunities presented by the Covid-19 lockdown appear to have yielded more violence than family bonding especially our emphasis on household rape.

Until sometime in 2019 when Mrs. Busola Dakolo reported against Pastor Biodun Fatoyinbo of Commonwealth of Zion Assembly (COZA) of sexual assaults, it was not the culture for victims of rape in Nigeria to make it open (Kilete, 2019:5). Furthermore, the Nigerian society appears to be the men's world that even the 1999 Constitution of the Federal Republic of Nigeria 
is clear that rape is incomplete except upon penetration. This has two implications in terms of executing the law. How is penetration measured? Must rape be a masculine affair only since penetration is done by men during sexual intercourse? The United Nations definition of sexual and gender-based violence as "violence that is directed against a person based on gender or sex. It includes acts that inflict physical, mental or sexual harm or suffering, threats of such acts, coercion and other deprivations of liberty" (Ismael, 2021).

Before the COVID-19 lockdown, the rising profiles of sexual violence in Nigeria especially in the tertiary institutions was so alarming especially with the cases of two lecturers at the University of Lagos, a Professor of Obafemi Awolowo University Ile-Ife and recently two lecturers of Imo State University Owerri. It was circumstances such as this, that led the Deputy Senate President of Nigeria Ovie Omo-Agege to sponsor the Sexual Harassment Bill which seek to criminalize all acts of sexual violence in 2020 (Expeditions Passage of the Sexual Harassment Bill,2020:15). The sexual Harassment Bill if fully enacted, Nigeria will be fulfilling part of its obligation undertaken through its ratification of the United Nations Convention on the Elimination of All Forms of Discrimination Against Women (CEDAW), African Charter on Human and People's Right of Women in Africa, and African Charter on the Rights and Welfare of the child, among others (Itua and Orji, 2020:6). One of the Sustainable Development Goals (SDGs) is Goal 5, which is the achievement of gender equality and empowerment to all women and girls. Three out of the targets of the goal are: firstly, putting an end to all forms of discrimination against all women and girls, secondly, the elimination of any forms of violence on women and girls anywhere, and thirdly, the elimination of every form of practices (female circumcision, early and forced marriage) that can cause abuse and trauma to women and girls4. Rape can be classified as one of the violence against women and girls because it is an act of forcefully having sexual intercourse with someone without any mutual agreement. Globally, COVID-19 pandemic is causing a lot of serious havoc, Nigeria is not excluded (Abulude and Abulude, 2020).

The COVID-19 pandemic outbreak resulted to increase in sexual and domestic violence against women. The Coronavirus pandemic lockdown was a period of tension and sober reflections for so many people but it was also a period of extreme sexual violence as this study reveals. Odife (2020:9) quoted police report of May 2020 which has it that since the COVID-19 lockdown about 717 cases were recorded (that's between March and May 2020) and from May to June 2020 about 799 extra cases of rape was reported. The incessant cases of rape during COVID19 during the lockdown was brought to limelight by the case of 22-year-old Vera Uwaila Omozua a first-year student of microbiology of the University of Benin who was raped and killed in a church building in Benin city on May 13 2020. (Akinrinade,2020:11). In a related case, Barakat Bello a 18 year old National Diploma student of Federal College of Animal and Production Technology was raped to death on 1 June 2020 (Ekpu, 2020:31). The passage of sexual harassment bill is being contested because it proposed 14 years jail term for offenders and five years for any person convicted for demanding sex, intimidating a student, acts of touching and sending sexual advances to a student and even having sex with her consent is considered an offence (The Passage of the Sexual Harassment Bill,2020:11).

The pandemic has worsened escalating issue of rape as a total of two million Nigerians are raped every year (Special Court for Rape Cases,2020:11). Available records indicate that by the second week of July 2020, Africa recorded 559,446 cases to COVID-19, 12,769 death and 271,826 
recoveries from COVID-19 pandemic. It took 100 days for the continent to reach 100,000 cases but 18 days to increase 200,000 and 20 days to get to 400,000 cases (Stemming Rising Cases of COVID-19 in Africa, 2020). A World Health Organization report has it that Covid-19 pandemic outbreak led to the closure of Sexual and Reproductive Health Services leading to 9.5 million vulnerable women and girls losing access to contraception and safe abortion in 2020. Its significant effect is that an estimate of about 11,000 pregnancy related deaths are inevitable with about 2.7 million unsafe abortions (Kanem, 2020).

Apart from rape, other forms of domestic violence against women like Female Genital Mutilation were reported in so many places in Africa including Nigeria. It was observed that the COVID-19 pandemic was reversing the progress being made in child marriages and Female Genital Mutilations (FGM) with about 33,000 girls being forced into marriages to older men and about 4.1 million subjected to FGM according to the United Nations Population Fund(UNPF)(Pandemic Increases Risk of Female Genital Mutilation,2020).In Portharcourt city south-south Nigeria, there was sexual violence in a church premise of the Great Mercy Deliverance Ministry where baby factory business was ongoing during the lockdown. Several women were kept in a place and were being impregnated and their babies were to be sold upon delivery (Okezie-Okeh, 2020:4). Elsewhere, Okonkwo and Obi-Ani (2020:408) recorded that: "baby factory is a phenomenon that involves the trading of mostly women for the purposes of forced labor, sexual slavery or commercial sex exploitation"

At a Chinese owned firm situated in Onitsha, a report by Kaosisochukwu Enemuo that Chinese expatriates was in the habit of sexually harassing women during the lockdown especially workers in the factory situated at Onitsha Industrial Harbour Anambra State (Agbodo,2020:7). Following the reports of sexual violence during COVID-19 pandemic, Abuja, Kaduna and Lagos recorded the highest number of sexual abuse cases during the pandemic appeared as follows: Abuja $58.8 \%$, Kaduna 47.2\%, Lagos 46.5\%, Kwara 27.9\% and Kano 28.4\% (Obogo, 2020:26).

The available data on sexual violence is scanty and fragmented. Many women and girl children do not report the sexual violence meted on them to the police because they were ashamed or fear of being blamed, not believed or otherwise maltreated. Teenage and underage girls are daily abused but hardly do the survivors or their families speak out. The society they live in would instead pressure survivors not to press for charges, or the parents would rather keep quiet to "protect the dignity" of the girl-child growing up. Many would instead look unto God for justice because they could not afford the process of litigation. As such, most of such cases die at the police station. This was evident by Magdalene, 19-year-old girl, a resident of Abagena IDP camp in Markurdi. Abagena is home to more than 8,000 IDPs, according to an official of the State Emergency Management Agency. Magdalene has lived in the camp for four years. She observed that the culture of silence instituted by the camp authorities has given rise to a generation of children born from rape. In her word she said that:

"Attempts to retrieve data on reports of rape, harassment, or other forms of sexual abuse in Abagena were denied by camp staff. Rather, Magdalene said, incidents are settled in hushed tones. Victims are often threatened to stay silent or risk eviction- especially if the abuser is a camp official -said Magdalene, given what she's heard of the experiences of women who've left the camp for that reason" (Ugwa, 2021) 
In the camp, the culture of *'Kwambe sa Kwambe' *(loosely translated to "You scratch my back, I'll scratch yours" in the Tiv language) applies," Loho said, especially when it comes to an IDP offering sex to officials in exchange for food or provisions. Ngunan Ioron Loho is the founder of the Samuel Ioron Foundation (SIF). A non-profit providing educational access and inclusion for girls in Benue's IDP camp (Ugwa, 2021). During the COVID-19 lockdown, more than 3,600 rape cases were recorded across Nigeria --- and that could still be a gross undercount, given the lack of data on violence against women. Even before the pandemic hit, rape victims were less willing to report cases due to lack of faith in the country's snail-paced legal system. But during the lockdown, though mobile courts were operating, cases of abuse --- especially sexual and domestic abuse -- were deprioritized (Ugwa, 2021). Relevant materials for this paper have been sourced from newspapers, online publications in journals, and books while the descriptive method of analysis has been adopted.

\section{The Lockdown and the Rising Profiles of Rape Cases}

Rape and related sexual violence happen every day in many parts of Nigeria. But it is more prevalent in environments where structures needed for the protection of the victims are missing. Places like camps for persons displaced by Boko Haram or any other kind of conflict leave the female-child particularly more vulnerable to rape.

There is total absence of strong database from the Nigerian Police on sex offenders in Nigeria. For example, from January to August 2020, police recorded 700 cases of rape whereas available evidence as already mentioned surpasses this record (Taiwo-Obalonye $\left.{ }^{A}, 2020: 19\right)$. There was also a new dimension to COVID-19 cases of rape as $93 \%$ of victims were raped by their family members, uncle or parent. At the beginning of the lockdown in March 2020, a 17-year-old young man Junior David of Onogholo village in Ubiaja, Esan South-East Local Government Area of Edo State was apprehended for raping a 75-year-old woman Madam Helina Aborsi. Still in the same area, a 65year-old clergy man Rev. John Imoagadama of Advance School of Theology was also caught for raping a 14-year-old girl Divine (Uwajare,2020:8).

The Federal governments following some of these developments pushed for the domestication of the Violence Against Prohibition Act (VAPPA) in states across the federation that will address the issue of sexual violence in Nigeria. There are many reasons for the increase rate of home sexual violence. Ordinarily, Nigeria is a country with zero level tolerance on bisexuality, homosexuality or lesbian cultures. Moreira and Pinto da Costa (2020) reveals that women in heterosexual relationship appear to represent the overwhelming majority of victims of sexual violence as witnessed with the Covid-19 lockdown. On the other way round, only five states in Nigeria have laws against sexual and gender-based violence and Lagos and Ekiti tops the list (Ezeh, 2020:11).

The National Agency for the Prohibition of Trafficking in Persons (NAPTIP) on 10 ${ }^{\text {th }}$ June 2020 confirmed that no fewer than 80 cases of rape were recorded in Anambra State during the COVID19 lockdown and compared it with the sexual offences register in Anambra state in the year 2019

which had 78 cases,51 in court and 12 convictions. The Director General of NAPTIP blamed lack of proper parenting, access to sophisticated internet which exposes children to sexual issues, parents leaving their children for drivers, uncles, housemaids, and family members without proper 
check as $90 \%$ of rape cases during the lockdown was committed by family members (Ezeh, 2020:11). Regrettably, Taiwo-Obalonye ${ }^{B}$ (2020:11) reported NAPTIP is investigating to know why a man of 80,75, 60 will rape a child of one or two years. Furthermore, he noted that hundreds of cases of rapes in courts are yet to be addressed and only one out of ten cases of rape are being reported.

The impact of Covid-19 on the rising profile of domestic violence has been examined. Ertan et. al., (2020) insists that the Covid-19 pandemic induced stress have economic, social and psychological consequences. In their own analysis, Sharma and Borah (2020:2) have argued that the effects of natural disaster and lack of health care in post disaster era make women vulnerable to reproductive and sexual health issues and increase the incidence of domestic and sexual violence. In May 2020 at the height of the COVID-19 lockdown, a forty eighty years old Femi Onifade in Akure in South Western Nigeria was accused of defiling her two daughters (Gbolagunte,2020:5). In Urhobo area of Delta State, there was a case of a sexagenarian of 65 years who raped his neighbour's child of four years daughter (Kilete,2020:17). He felt so remorse when caught and from his confessions he had slight mental problem and absentees from sex for a short period of time was responsible for his actions. According to him:

I have been to many hospitals to cure the ailment but I have not been able to get a solution. My children know about my ailment but they don't know that I rape children. They have taken me to Wuse General Hospital and I get treated periodically when it starts and they usually prescribe drugs for me that take my mind of these bad things (Kilete ${ }^{\mathrm{A}}$,2020:17).

Furthermore, the report reads:

I am not a womanizer because I have a wife and had sex two months ago. My wife stays Ado, we were together in Mabushi where I built my own house. Two months ago I was at Ado to visit my wife and that was the last time I had sex (Kilete ${ }^{A}, 2020: 17$ ).

The reasons for the incessant cases of rape have been a challenging hypothesis to researchers and reporters. Omegoh and Anyanwu (2020:4) recorded that:

Of course, the truth is that there are many out there who do not have control over their sexual orgies. They probably don't have money to visit the brothels or probably their wives were not there for them, yet they must poke their thing inside a hole. So, what happen next? Every woman they saw around them became a target. And the result is what we are seeing now"

The Covid-19 pandemic had impact on people's patronage to prostitutes. This is because many customers could not come or have no excuse to do so in order to patronize commercial sex workers during this period (Tsa, 2020:21). The closure of many brothels did not help matters as well. The case of a 25 year old man who raped a seven years old girl that was treated at Abubakar Tafawa Balewa University Teaching Hospital (ATBUTH) was reported in July 2020 and there was still a case of a 33 year old man from Kano who was caught for raping a total of 40 women in a year (Mgboh,Orude and Folaranmi,2020:5) 
From the legal point of view, there have been efforts to reprimand those involved in rape. Two people felt into this net, a 40-year-old electrician Monsuru Ojo and John Jester a 42-year-old man have been reminded in prison custody by the Chief Magistrate Court Ikeja for raping his friend lover and the defilement of a 12-year-old daughter (Okoye, 2020:5). In August 2020, two siblings in Minna Niger State were sentenced to 22 years imprisonment for raping four minors (Brothers Jailed 22 Years for Rape, 2020). Age limits and social status has nothing to do with the restrictions on what people sexual behavior could turn to. In Osun State, the Magistrate Court in Osogbo ordered in May 2020 that a 62-year-old traditional ruler David Ogungbemi, his son Idowu Ogungbemi and one Sarafa Olayiwola be kept in prison for allegedly defiling a 14-year-old girl (Otabor, 2020:4). In Lagos, an Ikeja Magistrate Court reminded a 33-year-old unemployed Riliwan Salim to prison custody in August 2020 for defiling a five-year-old girl (Oyesola, 2020:21). In Markudi, a Benue Magistrate Court reminded a 38-year-old man Simon Emeka in prison custody for defiling his seven months daughter (Man,38, Rapes, 2020:4)

With the incessant cases of rape cases on going in Nigeria during the lockdown, awareness campaigns began to spread in order to curtail this social dilemma. A non-governmental organization like Project Alert led by Josephine Effah-Chukwuma was able to contribute its own quota. The group observed that one of the factors responsible for the repeated cases of rape was culture of silence. The rapists during the COVID-19 lockdown were identified as siblings, playmates, family members, teachers, coaches, instructors, caretakers or parent of another child taking advantage of child's vulnerability to manipulate, coerce and intimidate the children into silence (Alaka, 2020:39).

In August 2020, a webinar on sexual violence reported the paper presentation of Professor Ayodele Atsenuwa that child defilement accounted for 60 percent of sexual offences in Lagos. The risk factors in child defilement were identified as lack of parental care or support, cultural, poor reporting and impunity, peer pressure especially among adolescents, poor training of teachers and caregivers. Also reported is that between January to August 2020, there was 981 sexual offences in Nigeria, 586 cases of child defilement representing 60 percent,207 rape cases representing 21 percent while 188 representing other forms of sexual abuse represented 19 percent (Onanuga,2020:14). In a similar development, Igbo women under the auspice of Umuada Igbo Nigeria and Diaspora during the 2020 August meeting-a platform used by women to discuss issues affecting their communities raised alarm over the rising rate of rape cases. They were not alone as they had collaboration with a gender-based advocacy group in Enugu known as Women Aid Collective (WACOL) who claimed that they received a total of 153 cases of rape between June and July 2020 (Anyanwu, et. al., 2020).

The announcement of lockdown and ban in interstate travel from March to June 2020 was enforced by the police and other security agents in order to ensure compliance. The National Human Rights Commission (NHRC) noted in April 2020 that while 11 people have died as a result of the Coronavirus, 18 people were killed by security agents while trying to enforce the ban on movement during the lockdown. The Commission noted that the security agents have carried out 33 incidents of torture, 27 incidents of violation of freedom and cases of police brutality were recorded in Kaduna, Abia, Delta, Niger, Ebonyi and Katsina (Ugwu, Ezeh, Kilete, Attah and Dunno,2020:8) 


\section{The Internally Displaced Persons and the Covid-19 Lockdown}

The rising profile of internally displaced persons in Nigeria began to take this ugly trend in 2010 at the height of Boko Haram insurgency. The intensity of the terrorist attacks implies increase in the number of Internally Displaced Persons (IDP) and camps. As a sovereign government, the Nigerian state has failed to address the huge challenge posed by the welfare of this vulnerable category of citizens in terms of shelter, food and education. Sometime in August 2016, the Nigerian Senate President Bukola Saraki vowed to investigate severe hunger and nutrition crisis that was a challenge to the Internally Displaced Persons in northeast Nigeria (Umoru and Erunke, 2016:9) This intervention came as a follow up of the result of the protest in August 2016 when mostly women in their hundreds barricaded the Maiduguri-Kano/Jos Road over alleged shortage of food supply by the government. Also raised by those in the IDPs was the issue of prostitution ongoing in the camp in order to feed (Marama, 2016:8-9).

In 2018, following the herdsmen attack on many Benue communities like Agatu, there was over 100,000 displaced persons in various camps across the state as result of the introduction of antigrazing law against herdsmen who went on rampage (Uja, 2020:13-15). According to Federal Commissioner for Refugees, Migrants and Internally Displaced Persons (NCRMIDP) Senator Basheer Mohammed revealed that 290 Internally Displaced Persons camps exist in Nigeria with a population of 2.3 million. This has been the outcome of the Boko Haram terrorist ravaging states of Borno, Yobe and Adamawa states (Yahaya, 2020:10). During the lockdown thus noted Yahaya (2020) it was difficult amidst hunger to maintain social distancing in the IDPs camps. For example, the Durumi camp in Abuja accommodates 2,830 inmates comprising of men, women, young adults and children. In the Internally Displaced Persons camp in Ohogua, Ovia North East Local Government of Edo State there was decry over the unavailability of essential drugs for malaria and antibiotics that will take care of about 4,000 persons (Osauzo,2020:42). According to the Christian Aid Emergency Humanitarian Relief Fund, Benue alone has more than 50,000 IDPs from attacks, which have led to the loss of almost 1,000 lives (Ugwa, 2021). Nigerian law specifies a minimum of 12 years imprisonment for rape offenses without the option of a fine.

While efforts were being put in place to address the quagmire created by the activities of Boko Haram insurgency, the activities of the bandits and cattle rustlers attacking communities in northeast Nigeria created yet another Internally Displaced Persons (IDP) camp in Goronyo Local government Area of Sokoto (Omolehin,2020:44). The COVID-19 lockdown was taking place at the same time the insurgency in northern Nigeria was busy creating more Internally Displaced Persons without proper care from the government especially the serial looting of the economy that is still ongoing up to the point of writing. In Borno alone, a record case of 56,000 IDPs across the 20 councils exits while in Bakassi Camp there are about 44,000 IDPs comprising over 20,000 male and female households. The problem of these vulnerable groups of Nigerian citizens is the total neglect from the government as they prefer to rehabilitate repentant Boko Haram members while those they killed their relatives, houses and properties are allowed to die in hunger and grief (Akubo, Ande and Oyewale, 2020:2) 
The orphanages across the length and breadth of Nigeria were also suffering as visitors were restricted from coming to their premises in order to avoid community spread. Second, the government was not supporting the vulnerable in the practical sense of it. The introduction of elearning due to COVID-19 lockdown eluded this category of citizens who have no access to basic amenities like electricity, computer, television and other e-learning apparatus because those IDP camps are not catered for (Taiwo-Obalonye ${ }^{c}, 2020: 14$ ). The outbreak of Covid-19 pandemic in north east with a total of 394 confirmed cases in June 2020 was a threat to the IDP camps in the region. This is with 358 cases in Borno representing 76 percent of all the cases, Adamawa recording 38 and 49 cases for Yobe (Olanrewaju, 2020:29). Roesch et al advocates for the need to provide mobile health and telemedicine that will cater for displaced persons (Roesch,2020:1-2). Nigeria is an excellent theatre of experimenting this idea.

Ugwa (2021) notes that Women make up more than 50 percent of the IDP population in Nigeria. And as they are forced to survive on less than $\$ 780$ (US \$1.90), their livelihoods are largely reliant on goodwill donations from charitable and government organizations. Consequently, due to overlapping vulnerabilities related to economic security and protection, many find themselves at risk of sexual and gender-based violence in the camps. The condition of people living in the IDPs camp during the COVID-19 lockdown was a challenge to the conscience of not only the Nigerian government but the global community. The Japanese government donated 474,272 USD to the Internally Displaced Persons in Nigeria with a target population of 1.8 million since the beginning of Boko Haram insurgency in Nigeria in 2010 (Aidoghie, 2020:10). There was also generous donation of 26 million Euros from the German government to the Internally Displaced Persons in Nigeria (Emeozor, 2020:29). Unfortunately, in spite of these financial interventions nothing suggests that those in IDPs camp are being catered for.

\section{Conclusion}

The incessant cases of sexual violence during Covid-19 pandemic could be traced to issues of mental imbalance, inability to control one's sexual orgy and the growing rate of moral hopelessness. It has been revealed that parenting in recent times is worrisome but more especially caregivers and teachers of all level must be engaged again especially the moral aspect of their profession. In addition, the terrorist attack that has been ongoing in Nigeria in the last ten years has created a lot of displacements making people vacate their homes. The IDPs camp are not well taking care of and the outbreak of COVID-19 was a major setback to already worse situations especially feeding, medical care and social distancing when there is no space. In all, the conduct of the Nigerian Police Force during this lockdown is bereft of minimal standard of dealing with human rights questions as shown in this paper.

\section{References}

Adiele, P. (2020). "COVID-19: Police and Military Brutality" Daily Sun Wednesday April 29

Agbodo, J.A. (2020). 'Rape Scandal Rocks Chinese Factory in Anambra' Saturday Sun, July 18 
Agusi, E.R et al (2020). 'The COVID-19 Pandemic and Social Distancing in Nigeria: Ignorance or Defiance" The Pan Africa-Medical Journal, Vol.33 Supp 2

Aidoghie, P. (2020). 'Germany Donates 26 million Euro for Humanitarian Assistance" Daily Sun, Tuesday June 9

Akinrinade, K. (2020). 'Murderous Rapists on the Prowl' The Nation, Saturday June 13

Akubo, J., Ande, E., and Oyewale, R. (2020) 'IDPs: We Will Never Forgive Our Oppressors"' The Guardian, Saturday August 15

Alaka, G (2020). 'Sexual Violence: Danger is Right in the House" The Nation, Sunday March 8

Anyanwu, C.G et al. (2020). 'Igbo Women Battle Rape' Daily Sun, Wednesday September 9 Brothers Jailed 22 Years for Rape (2020) The Nation, Thursday August 18

Commentary (2020.) 'Police and Incoherent COVID-19 War" The Nation, Saturday May 23

Ekpu, R. (2020). "COVID-20 Pandemic" Daily Sun, Tuesday June 9

Emeozor, E. (2020). "Germany Donates 26M Euro for Humanitarian Assistance" Daily Sun, Tuesday, June 9

Ertan, D. (2020). 'COVID-19: Urgency for Distancing from Domestic Violence' European Journal of Psychotraumatology, http://www.tandfonline.com/ioi/zept20

Expeditious Passage of the Sexual Harassment Bill (2020) Daily Sun, Friday, March 20

Ezeh, F. (2020). "Anambra Recorded 80 Rape Cases During Lockdown Says NAPTIP" Daily Sun, Thursday, June 11

Gbolagunte, B. (2020). "I didn't Rape My Daughters-Suspect" Daily Sun, Tuesday May 26

Igbokeyi, F. (2020). 'Stray Bullets Kills One, As Suspected Yahoo Boys Protest Police Extortion in Delta" Daily Independent, Tuesday August 4

Itua, F and Orji, N (2020). 'Fireworks in Senate Over Sexual Harassment' Daily Sun, Wednesday July 8

Kanem, N (2020). 'COVID-19 Has Devastating Effect on Women Crisis-World Health Report" www.thelancent.com Vol.396 August 1

Kilete, M. (2019). "COZA: IGP Orders FCID to take Over Rape Allegation" Daily Sun, Tuesday July 23

Kilete, MA. (2020). " Grandpa From Hell: Sexagenarian Rapes Neighbours 4-Year-Old Daughters Blames Mental Illness" Daily Sun, Wednesday July 1

Kilete, $M^{B}$ (2020)'Protest Rocks Abuja Over Killing of 52 Year Old Man by Police" Daily Sun, Tuesday May 12

Kumar, A. (2020). 'COVID-19 and Domestic Violence: A Possible Public Health Crisis, Journal of Health Management,22(20

Man, 38, 'Rapes' Seven-Month-Old Amidst Nation Wide Outcry (2020) The Nation, Monday June 8

Marama, N. (2020). 'Food Crisis, Malnutrition, Prostitution Rock IDPs Camp" Sunday Vanguard, August 28

Moreira,D.N and Pinto da Costa, M.(2020). 'The Impact of the Covid-19 Pandemic in the Precipitation of Intimate Partner Violence' International Journal of Law and Psychology, Vol.71

Obogo, C. (2020). "COVID-19 Lockddown:Abuja, Kaduna,Lagos Record Highest Cases of Sexual Violence" Daily Sun, Wednesday, September 2

Odife, S. (2020). 'Rape As Another Pandemic' Daily Sun, Thursday July 2 
Okezie-Okeh, C. (2020). 'Baby Factory in the Church' Saturday Sun, July 4

Okonkwo,U.U. and Obi-Ani, N.A. (2020). Women and the Upsurge of "Baby factories" in Southeastern Nigeria: Erosion of Cultural Values or Capitalism? Journal of International Women's Studies Vol. 21, No. 6 August

Okoye, R. (2020). 'Gale of Rapes in Lagos" Daily Sun Friday July 24

Okwor, L (2020). 'Enugu COVID-19 Surge: It is Time We Took Responsibility" Sunday Sun, July 5

Olanrewaju, T. (2020). 'COVID-19: WHO Raises Concern Over Rising Cases in North East,IDPs Camps" Daily Sun Tuesday June 9

Omegoh, C and Anyanwu, C. (2020). "Outrage Condemnation Trial Rise in Rape Cases" Daily Sun, Daily Sun August 16.

Omelehin, T. (2020). "President Buhari Assures Victims of Banditary,IDPs in Sokoto" Daily Sun, Thursday, July 23

Onanuga, A. (2020). "Don, DPP Blame Parents, Community Leaders for the Rise in Child Defilement" The Nation, Tuesday August 18

Osauzo, T. (2020). 'Edo IDDPs Management Raises the Alarm Over Epidemic Outbreak" Daily Sun, Tuesday July 23

Otabor, O. (2020). 'Man, Son Held for Raping Minor in Osun", The Nation, Friday May 15

Oyesola, B (2020). "Waging War Against Scourge of Rape, Sexual Violence" Daily Sun, Monday August 24

Pandemic Increase Risk of Female Genital Mutilation for Millions-UN (2020) Daily Sun, Wednesday, July 1

Roesch, E et al (2020). 'Violence Against Women During Covid-19 Pandemic Restrictions', Vol.369 May

Salaudeen, O (2020). "Mohammed Adamu: IGPs Curfew Burden and COVID-19 Frontline Workers" Daily Sun May 24

Sampson, O (2020). "Protest Rock Aba on NSCDC Officer Kills Man" Daily Sun Thursday September 10

Sharma, A and Borah, S.B. (2020). 'COVID-19 and Domestic Violence: An Indirect Path to Social and Economic Crisis" Journal of Family Violence, http://doi.org/10.007/s/10896-020-00188-8, July

Special Court for Rape Cases" (2020). Daily Sun, Tuesday July 7

Stemming Rising Cases of COVID-19 in Africa" (2020) Daily Sun, Tuesday July 21

Taiwo-Obalonye, JA. (2020). "Rape War in Abuja" Daily Sun, Wednesday August 12

Taiwo-Obalonye, JB. (2020) "FG Declares War on Rapists" Daily Sun, Thursday June 11

Taiwo-Obalonye, JC. (2020). "Bearing the Covid-19 Brunt: Abuja Orphanages in Distress As Lockdown Inflicts Hardship on Children, Staff" Daily Sun, Tuesday May 12

The Passage of the Sexual Harassment Bill (2020) Daily Sun, Tuesday July 23

Tsa, G. (2020). 'COVID-19: Abuja Prostitutes Broke' Daily Sun, Wednesday, May 20

Ugwu, R et al (2020) 'Lockdown Turns Bloody" Daily Sun, Thursday April 16

Uja, E. (2020). "Benue IDPS to Fed. Government: Save Us from Looming Danger" The Nation, Saturday January 18

Ukeh, O. (2020). "Discordant Times in the Fight Against COVID-19" Daily Sun, Friday May 22 
Umoru, H and Erunke, J. (2016). "Senate Will Investigate IDPS Hunger/Nutrition Crisis-Saraki" Sunday Vanguard August 28

UNCHR The UN Refugee Agency. (2020). 'Preventing Forcibly Displaced Women and Girls During the Covid-19 Pandemic" July

Uwujare, N. (2020). 'Tales of Two Rapists" Saturday Sun March 28

Yahaya, F (2020). "How Inmates of Abuja IDP Camps Coped with the Lockdown" The Nation, Wednesday, May 6

Ugwa, J. (2021). Sexual Abuse Thrives in Nigeria's IDP Camps with No Recourse for Victims

Ismael, O. (2021). Covid-19 and Sexual and Gender-Based Violence

in the Lake Chad Basin. (C) 2021, United Nations Development Programme Place de la Grande Armée, B.P. 727, N'Djamena, Tchad Commission du Bassin du Lac Tchad

Abulude F. O. and Abulude, I. A. (2020). Rape: A Violence Against Women and Girls During Covid-19 PandemiciIn Nigeria

\section{Bio-Notes}

Joy Nneka U. Ejikeme PhD is a lecturer in Humanities Unit, School of General Studies University of Nigeria, Nsukka.

Iwundu Ifeanyi E. PhD is a Senior Research Fellow, Institute of African Studies, University of Nigeria, Nsukka.

Ogechi Cecilia Ukaogo is a staff in Careers Unit, Registrar's Office, University of Nigeria, Nsukka. 